\title{
A Case Report of Uncommon Cause of Cyanosis in a Child
}

\author{
Amel AM Elfaramawy ${ }^{\mathrm{a}, \mathrm{b}}$, Ola A Elmasry ${ }^{\mathrm{a}}$
}

\begin{abstract}
Pulmonary complications may occur as a result of end-stage liver disease, probably due to decreased hepatic clearance or increased hepatic production of circulating cytokines and other vascular growth mediators. We report a case of a female Egyptian patient 15 -year-old that presented with cyanosis who was investigated for a long time for being a cardiac patient as she showed no symptoms suggestive of liver affection but eventually she was diagnosed to have hepatopulmonary syndrome. We aim to highlight pulmonary affection secondary to hepatic disease that although rare can lead to significant morbidity in patients with liver cirrhosis.
\end{abstract}

Keywords: Hepatopulmonary syndrome; Liver cirrhosis; Intrapulmonary shunts; Cyanosis

\section{Introduction}

Advanced liver disease and portal hypertension produce various intrathoracic complications that involve the pleural space, the lung parenchyma, and the pulmonary circulation

Manuscript accepted for publication August 23, 2011

${ }^{\mathrm{a}}$ Faculty of Medicine, Ain Shams University, Cairo, Egypt, Ola A Elmasry, Egypt

${ }^{\mathrm{b}}$ Corresponding author: Amel Elfaramawy, 15, Abou Elmahassen st, Roxy, Heliopolis, Cairo, Egypt. Email: amelhome4@gmail.com

doi:10.4021/ijcp103e
[1]. These complications include hepatopulmonary syndrome (HPS), portopulmonary hypertension (POPH) and hepatic hydrothorax [2]. Additionally, mechanical factors may lead to thoracic complications, such as cephalic displacement of the diaphragm by increased abdominal pressure and ascites with resultant dyspnea, and passage of ascites from the peritoneal space to the pleural space through diaphragmatic defects resulting in hepatic hydrothorax [3].

HPS is defined clinically as the triad of chronic liver disease, abnormal pulmonary gas exchange with an increased alveolar-arterial oxygen gradient, and evidence of pulmonary vascular dilatations [4]. HPS is primarily a gas exchange problem characterized by arterial hypoxemia [5]. The prevalence of HPS in the setting of cirrhosis ranges between 4\% - 30\% [6]. The European Respiratory Society has proposed a classification system that uses arterial oxygen tension $(\mathrm{PaO} 2)$ to stage the severity of HPS, as a means of predicting survival and determining the timing and risks of orthotopic liver transplantation. According to this system, a $\mathrm{PaO} 2<50 \mathrm{mmHg}$ indicates very severe HPS, a $\mathrm{PaO} 2$ in between 50 to $60 \mathrm{mmHg}$ suggests moderate HPS and a $\mathrm{PaO} 2$ in between 60 and $80 \mathrm{mmHg}$ corresponds with mild HPS [7].

$\mathrm{POPH}$, on the other hand, is best defined as pulmonary artery hypertension (PAH) associated with portal hypertension, whether or not that portal hypertension is secondary to underlying liver disease, and its diagnosis is traditionally based on hemodynamic data from right heart catheterization [8]. POPH is primarily a hemodynamic problem which can result in right heart failure and death [5]. Recent work using hemodynamic studies have estimated the prevalence of POPH to be between $2 \%$ and $5 \%$. The prevalence in patients undergoing liver transplantation (LT) is probably higher, with one study showing a prevalence of $8.5 \%$ [8].

\section{Case Report}

A 15 year old girl presented to the Out-Patient clinic of the Children's Hospital, Ain Shams University with cyanosis and shortness of breath of 4 years duration. Her condition started 5 years prior to presentation with abdominal enlargement; hepatomegaly and lymphadenopathy. Malignancy was 
suspected and a surgical biopsy was taken from the intraabdominal lymph nodes. The pathological examination excluded malignancy but raised the possibility of tuberculosis, with subsequent antituberculous treatment for 2 years.

Abdominal distension did not persist after the open biopsy. However the mother noticed that her child developed progressive cyanosis, with dyspnea, tachypnea, easy fatigability and deterioration in her general condition. The child did not complain of any symptoms suggestive of liver disease. She was not jaundiced, and there had been no change in the color of urine, no hematemesis and no abdominal distension at that time.

Echocardiography was done repeatedly and showed a structurally normal heart with a patent foramen oval $(4 \mathrm{~mm})$ shunting from left to right, and mild tricuspid regurgitation with an estimated peak right ventricular systolic pressure of $26 \mathrm{mmHg}$. Cardiac catheterization showed normal pulmonary artery pressure of $25 / 10 \mathrm{mmHg}$, right ventricular systolic pressure of $28 \mathrm{mmHg}$ and end diastolic pressure of 8 mmHg. Oxygen saturation was $74 \%$ in the aorta, $61 \%$ in the right ventricle and $63 \%$ in the pulmonary artery Angiography showed no evidence of fistulous communications to the pulmonary artery and normal pulmonary venous drainage. Multislice CT angiography was done 2 months later and showed confluent sizable PA branches with no evidence of pulmonary arteriovenous fistulae or aortopulmonary window. The lungs showed no evidence of interstitial lung fibrosis. During that time she was only on $\mathrm{O} 2$ therapy with no appreciable improvement.

When the child presented to our hospital a year later she was severely cyanosed, with third degree clubbing and mild jaundice. Her weight was $34 \mathrm{Kg}$ and height was 145 $\mathrm{cm}$, both below the 5 th centile for age. The heart rate was 87 beats/min, her respiratory rate was 35 breaths/min, and her blood pressure was $110 / 70 \mathrm{mmHg}$. She was markedly dyspneic with shallow breathing and she preferred to lie flat (platypnoea).

Cardiac examination revealed an accentuated second heart sound with an audible ejection systolic murmur (grade $2 / 6)$ over the pulmonary area. Chest examination was unremarkable. Abdominal examination revealed the paraumbilical scar of the previous biopsy. The right lobe of the liver was $5 \mathrm{~cm}$ below right costal margin in the midclavicular line and was firm in consistency with a sharp border. The spleen was palpable $4 \mathrm{~cm}$ below left costal margin.

Arterial blood gases in room air demonstrated a $\mathrm{pH}$ of $7.42, \mathrm{PaCO} 2$ of $28.0 \mathrm{mmHg}, \mathrm{PaO} 2$ of $20 \mathrm{mmHg}, \mathrm{HCO} 3$ of $18.1 \mathrm{mM} / \mathrm{L}$, and saturation of $35 \%$, which did not improve significantly on $100 \% \mathrm{O} 2$ inhalation.

A full blood count revealed hemoglobin of $12.6 \mathrm{gm} / \mathrm{dl}$, a hematocrit of $42.6 \%$, White blood cell count of $4.7 \times 10^{3} / \mu \mathrm{L}$, and a platelet count of $177 \times 10^{3} / \mu \mathrm{L}$. Her total bilirubin was $3.6 \mathrm{mg} / \mathrm{dl}$, with a direct bilirubin of $1.5 \mathrm{mg} / \mathrm{dl}$. Her serum albumin was $2.6 \mathrm{~g} / \mathrm{dl}$, ALT was $28 \mathrm{U} / \mathrm{L}$, AST $37 \mathrm{U} / \mathrm{L}$ and her
INR was 1.25 . Blood urea was $27 \mathrm{mg} / \mathrm{dl}$ and creatinine 0.6 $\mathrm{mg} / \mathrm{dl}$.

An anteroposterior chest $\mathrm{x}$ ray showed normal cardiac size and increased vascular markings of the lungs. Repeat echocardiography done at our institution showed normal cardiac structure, trivial tricuspid regurgitation with estimated peak RVSP $40 \mathrm{mmHg}$, and some turbulence across the RVOT into pulmonary artery. Contrast echocardiography with agitated saline demonstrated the appearance of bubbles in the left atrium after 4 beats, suggestive of intrapulmonary shunting.

Abdominal ultrasonography with Duplex study revealed hepatosplenomegaly with parenchymatous affection, enlarged portal vein (14 $\mathrm{mm}$ in diameter) with hepatofugal flow and an average velocity of $15 \mathrm{~cm} / \mathrm{sec}$, and congested lieno-renal collaterals. There was mild ascites, chronic calcular cholecystitis and multiple portahepatis and para-aortic lymph nodes.

The patient was diagnosed as having hepatopulmonary syndrome and placed on the liver transplantation list. Unfortunately the child collapsed at home and was admitted to the nearest hospital where she was admitted to PICU but arrested with failed resuscitation.

\section{Discussion}

In 1884 Fluckiger first described a woman with liver cirrhosis, cyanosis, and digital clubbing [9]. The term 'hepatopulmonary syndrome', the triad of liver disease, an increased alveolar-arterial gradient while breathing room air, and evidence of intrapulmonary vascular dilatations, was coined in 1977 by Kennedy and Knudson [10].

Hepatopulmonary syndrome manifests clinically as progressive dyspnea, cyanosis, and clubbing in a patient with cirrhosis. The insidious onset of dyspnoea, particularly on exertion, is the most common complaint but is non-specific. Platypnoea (shortness of breath exacerbated by sitting up and improved by lying supine) is a usual symptom [11].

Our patient demonstrated marked cyanosis and clubbing which was initially confusing as she was not known to be a hepatic patient and did not report any symptoms suggestive of hepatic affection.

Ruth and Wolfe 1994 [7] reported the case of an 11-year old boy with severe liver disease that started on the 2nd day of life .He was noted to have digital clubbing at the age of 9 years and over the next 2 years he developed dyspnea and cyanosis. His oxygen saturation was $68 \%$ and he had ejection systolic murmur grade II/VI over the left midsternal border. All the reported cases describe dyspnea and cyanosis and clubbing in well known hepatic patients after years of follow up either in children or adults [12].

It is generally assumed that the mechanism of hepatopulmonary syndrome is excessive vascular production of 
vasodilators, particularly nitric oxide, underlying the vasodilatation. At pathologic analysis, intrapulmonary vascular dilatations represent dilated precapillaries, direct arteriovenous communications, and dilated pleural vessels [13].

Contrast enhanced echocardiography is the preferred screening test for HPS. Differentiation between intracardiac and intrapulmonary shunting is based on the timing of when these bubbles are found in the left side chamber of the heart. In intracardiac right-to-left shunts, these bubbles appear in the left chamber of the heart within 3 heart beats of their appearance in the right chamber of the heart. In intrapulmonary shunts, these bubbles appear within 4 - 6th heartbeats [14].

Our patient demonstrated intrapulmonary shunting as evidenced by the appearance of agitated saline bubbles in the left atrium after 4 heart beats of their appearance in the right atrium during contrast echocardiography.

Since patients with advanced liver disease usually hyperventilate, hypocapnia $(\mathrm{PaCO} 2<35 \mathrm{mmHg})$ and respiratory alkalosis are common [15]. Orthodeoxia, defined as arterial deoxygenation accentuated in the upright position as opposed to the supine position is also reported [7] and this finding was present in our patient.

According to the European Respiratory Society classification system for HPS, our patient would have been classified as very severe since her $\mathrm{O} 2$ saturation was $35 \%$. Hansoti, and Sharma 1989 [16] also reported cases of similar severity in India. They reported 20 cases over a 20 -year period with arterial desaturation due to liver cirrhosis that was so severe so as to simulate congenital cyanotic heart disease. They reported the predominant occurrence of this condition in a younger age group and the invariable presence of an ejection systolic murmur at the pulmonary area, which further increases the resemblance to congenital cyanotic heart disease. This systolic murmur is almost certainly due to the hyperkinetic circulation. Hepatic and splenic enlargement is usual and point to the liver pathology [16].

Our patient highlights the importance of extensive history taking and clinical examination particularly in cyanotic patients in whom extensive investigations for cardiac, pulmonary and hematological causes are repeatedly negative. Additionally, although rare, patients with unexplained cyanosis should be assessed for long standing liver disease, especially children. Finally, contrast echocardiography with agitated saline is very simple, safe and cost-effective investigation to differentiate intra and extracardiac right to left shunts in patients with cyanosis and structurally normal hearts.

\section{Grant Support}

The authors declare that they did not receive any source of support, including financial, pharmaceutical or industry support. The authors declare that they did not receive any funding or grant from any organization.

\section{Conflict of Interest}

The authors have read and approved the manuscript.

\section{List of Abbreviations}

HPS: hepatopulmonary syndrome; POPH: portopulmonary hypertension.

\section{References}

1. Singh C, Sager JS. Pulmonary complications of cirrhosis. Med Clin North Am. 2009;93(4):871-883, viii.

2. Layden TJ, Kulik L. Hepatic manifestations of pulmonary diseases. Clin Liver Dis. 2002;6(4):969-979, ix.

3. Huffmyer JL, Nemergut EC. Respiratory dysfunction and pulmonary disease in cirrhosis and other hepatic disorders. Respir Care. 2007;52(8):1030-1036.

4. Almoosa KF. The Hepatopulmonary Syndrome. Hospital Physician 2000:23-30.

5. Umeda N, Kamath PS. Hepatopulmonary syndrome and portopulmonary hypertension. Hepatol Res. 2009;39(10):1020-1022.

6. Dollinger MM. Pulmonary complication of liver disease. Praxis (Bern 1994). 2006;95(40):1539-1542.

7. Ruth AB, Wolfe J. An 11-year-old boy with severe liver disease, cyanosis, and clubbing. Curr Opin Pediatr. 1994;6(3):280-285.

8. Golbin JM, Krowka MJ. Portopulmonary hypertension. Clin Chest Med. 2007;28(1):203-218, ix.

9. Flückiger M: Vorkommen von trommelschlegelförmigen Fingerendphalangen ohne chronische Veränderungen an den Lungen oder am Herzen. Wien Med Wochenschr. 1884, 34:1457-1458.

10. Kennedy TC, Knudson RJ. Exercise-aggravated hypoxemia and orthodeoxia in cirrhosis. Chest. 1977;72(3):305309.

11. Varghese J, Ilias-basha H, Dhanasekaran R, Singh S, Venkataraman J. Hepatopulmonary syndrome - past to present. Ann Hepatol. 2007;6(3):135-142.

12. Stratakos G, Malagari K, Broutzos E, Zakynthinos E, Roussos C, Papiris S. Dyspnoea and cyanosis in a cirrhotic patient. Eur Respir J. 2002;19(4):780-783.

13. Ghayumi SMA, Mehrabi S, Zamirian M, Haseli A, Lankarani KB. Pulmonary Complications in Cirrhotic Candidates for Liver Transplantation. Hepatitis Monthly. 2010; 10(2): 105-109.

14. Hind CR, Wong CM. Detection of pulmonary arteriovenous fistulae in patient with cirrhosis by contrast 2D echocardiography. Gut. 1981;22(12):10421044.

15. Nagata T, Matsumoto A, Uehara Y, Tanaka G, Oonuma 
H, Hara K, Igarashi K, et al. Oxygenation abnormalities in normoxemic patients with mild liver cirrhosis. Intern Med. 2002;41(6):435-440.
16. Hansoti RC, Sharma S. Cirrhosis of the liver simulating congenital cyanotic heart disease. Chest. 1989;96(4):843-848. 